EDUCATION

\title{
The attitude of patients towards medical students in a sexual health clinic
}

\author{
N Ryder, D Ivens, C Sabin
}

See end of article for authors' affiliations

.....................

Correspondence to: Dr Nathan Ryder, Marlborough Clinic, Royal Free Hospital, Pond Street, London NW3 2QG, UK; natryd@yahoo.com.au

Accepted for publication 4 February 2005
Sex Transm Infect 2005;81:437-439. doi: 10.1136/sti.2004.014332

Objectives: To determine patient attitudes toward medical students in the sexual health clinic, and to describe factors associated with patient refusal of medical student involvement.

Method: A self administered questionnaire was given to 259 consecutive patients attending the general genitourinary medicine clinic. Participants were asked to indicate their attitude to questioning and/or examination by medical students. Information was also collected on sex, age, ethnicity, and previous visits to sexual health clinics and previous exposure to medical students. The proportion of patients reporting comfort with student involvement, and association with age, sex, country of birth, language spoken, and previous experience of student and/or genitourinary medicine clinics are reported.

Results: $82.6 \%$ of patients agreed to participate. The proportion reporting feeling comfortable with students ranged from $64 \%$ for female students questioning them with a doctor present to $35 \%$ for a male student questioning them alone. Comfort levels were associated with the sex of the student and previous exposure to medical students, but not age, country of birth, language spoken, or previous attendance at a sexual health clinic. The most common reasons for feeling uncomfortable with students were privacy concerns and poorer quality of care.

Conclusion: Many patients feel uncomfortable with medical student involvement in a sexual health clinic consultation; particularly patients with no previous contact with medical students. Privacy and standard of care were the most common concerns, which are potentially amenable to change through better explanation of the students' role in the clinic.
$\mathrm{T}$ he attitude of patients towards the involvement of medical students in a sexual health clinic is currently unknown. In general medicine and gynaecology outpatient clinics a significant proportion of patients reported feeling uncomfortable having students present and disclosing personal information to them..$^{1-3}$

Surveys of medical schools in the United Kingdom carried out in 1984 and 1994 found a decrease in the time allocated to genitourinary medicine (GUM) training. ${ }^{45}$ Additionally, it was found that only one third of medical schools thought that at least $80 \%$ of graduating students would be able to take a sexual history, perform a genital examination, and have a good understanding of sexual health issues. ${ }^{4}$ This is occurring against a background where sexually transmitted infections (STIs) and HIV are increasing in incidence, and there is a growing shift of STI/HIV screening into a primary care setting.

The aim of this study was to provide data on the proportion of patients who would feel comfortable in allowing medical students to question and/or examine them, and on the factors that contribute to a refusal of patients to see students. This knowledge will allow training clinics to be structured in a manner that increases both students' learning opportunities and patient comfort levels.

\section{METHOD}

A self administered questionnaire was given to 259 consecutive patients on registration at the GUM clinic of the Royal Free Hospital, London. Participants were advised that a medical student would not be involved in their current visit, as the small number of dedicated teaching clinics were excluded from the study. Information was collected on gender, age, country of birth, language spoken at home, previous visits to sexual health clinics, and previous exposure to medical students. Participants were asked to indicate how strongly they agreed or disagreed with a set of statements regarding their feelings towards medical students (table 1). Participants gave their written consent and the trust's research ethics committee granted ethical approval.

For the purposes of analysis, the responses "agree" and "strongly agree" were combined as were "disagree" and "strongly disagree," proportions were compared using $\chi^{2}$ tests.

\section{RESULTS}

Of the 259 patients approached, 214 (82.6\%) agreed to participate. These 214 patients had a median age of 30 (range 16-80) years and $95(44.4 \%)$ were female. There were no significant differences between those agreeing to participate and those who did not in terms of either age or sex (data not shown).

Of the 214 patients who did participate, 124 (57.9\%) were born in the United Kingdom and 170 (79.4\%) spoke English at home. In all, 146 patients $(69.2 \%)$ had previously visited a sexual health or GUM clinic and 109 (51.9\%) had had previous contact with medical students. Patient responses to each of the six statements are shown in table l. Overall, the majority of patients reported feeling comfortable with having a student asking them questions with a doctor present in the room. Far fewer patients felt comfortable if a doctor were not present. Around half of patients felt comfortable with having a student examine them.

Where patients did express discomfort with having students present, the main reasons for this were related to issues of privacy $(25.2 \%$ of patients), receiving a lower standard of care $(22.9 \%)$, general concerns about a student examining the patient ( $17.8 \%)$, as well as a lack of control of

Abbreviations: GUM, genitourinary medicine; STI, sexually transmitted infections 
Table 1 Responses given by 214 patients* to each of six statements

\begin{tabular}{|c|c|c|c|c|c|}
\hline Statements & $\begin{array}{l}\text { Strongly } \\
\text { disagree }\end{array}$ & Disagree & Neutral & Agree & $\begin{array}{l}\text { Strongly } \\
\text { agree }\end{array}$ \\
\hline $\begin{array}{l}\text { (1) I would feel comfortable having a male medical student asking me } \\
\text { questions with a doctor present in the room }\end{array}$ & $8(3.8)$ & 21 (9.9) & $50(23.6)$ & $95(44.8)$ & $38(17.9)$ \\
\hline $\begin{array}{l}\text { (2) I would feel comfortable with a male medical student asking me } \\
\text { questions without a doctor present in the room }\end{array}$ & $34(16.1)$ & $46(21.8)$ & $58(27.5)$ & $51(24.2)$ & $22(10.4)$ \\
\hline $\begin{array}{l}\text { (3) I would feel comfortable with a female medical student asking me } \\
\text { questions with a doctor present in the room }\end{array}$ & $8(3.8)$ & $19(9.1)$ & $48(22.9)$ & $86(41.0)$ & 49 (23.3) \\
\hline $\begin{array}{l}\text { (4) I would feel comfortable with a female medical student asking me } \\
\text { questions without a doctor present in the room }\end{array}$ & $19(9.2)$ & $50(24.3)$ & $49(23.8)$ & $62(30.1)$ & $26(12.6)$ \\
\hline $\begin{array}{l}\text { (5) I would feel comfortable with a male medical student examining } \\
\text { me with a doctor present }\end{array}$ & $23(11.3)$ & $51(25.0)$ & $39(19.1)$ & $64(31.4)$ & 27 (13.2) \\
\hline $\begin{array}{l}\text { (6) I would feel comfortable with a female medical student examining } \\
\text { me with a doctor present }\end{array}$ & $15(7.3)$ & $45(22.0)$ & $42(20.5)$ & $72(35.1)$ & $31(15.1)$ \\
\hline
\end{tabular}

*Responses were missing for 2, 3, 4, 8, 10, and 9 patients for each of the six statements, respectively.

the student's level of involvement (7.5\%) and longer consultation times $(5.6 \%)$.

Responses generally differed according to the sex of the patient and whether they had previously been exposed to medical students (table 2). In particular, female patients were less likely than male patients to feel comfortable with a male student asking questions $(\mathrm{p}<0.01)$. In contrast, there were no differences in the proportions of male and female patients feeling comfortable with a female student asking questions. Female patients were less likely to feel comfortable with a male student examining them than were male patients $(p=0.0001)$; however, there was no difference between male and female patients when the question referred to a female student. There were no significant differences between male and female patients in the reasons given for any discomfort. Those who had been previously exposed to medical students in the past were more likely to feel comfortable with a male student asking questions or taking an examination $(\mathrm{p}=0.05)$. These two factors ( $\mathrm{sex}$ of patient and previous exposure to medical students) were unrelated, and so the latter finding could not be explained simply on the basis of a higher proportion of female patients in the group who had not previously been exposed to medical students.

\section{DISCUSSION}

Simons and co-workers found that one third of patients of a general internal medicine clinic preferred not to see students and a quarter felt uncomfortable disclosing "personal information" to the student. ${ }^{1}$ Other studies performed in obstetrics and gynaecology outpatient clinics have also shown a significant proportion of patients reporting feeling uncomfortable with students present. ${ }^{2}{ }^{3}$ The main factors found to contribute to refusal of student involvement were privacy concerns, lack of comfort with examination by the student and the gender of the student. Internal medicine and obstetrics and gynaecology patients with previous contact with medical students or who have previously attended the clinic were more likely to accept students.

We found a large proportion of patients reported feeling uncomfortable with medical student involvement in the GUM clinic, particularly if a doctor was not present in the room. This proportion was higher than other published studies, possibly reflecting the sensitive nature of many GUM consultations.

Female patients had particularly low comfort levels with male students, whereas male patients had less of a gender bias. This may lead to a poorer clinical experience for male students. As patients who reported previous contact with students were

Table 2 Relations between responses given to each statement and the sex of patient and previous exposure to medical students

\begin{tabular}{|c|c|c|c|c|c|c|c|}
\hline & & \multicolumn{3}{|c|}{ Sex of patient } & \multicolumn{3}{|c|}{ Previous exposure to medical students } \\
\hline & & \multirow{2}{*}{$\begin{array}{l}\text { Male } \\
\text { No (\%) }\end{array}$} & \multirow{2}{*}{$\begin{array}{l}\text { Female } \\
\text { No (\%) }\end{array}$} & \multirow[b]{2}{*}{ p Value } & \multirow{2}{*}{$\begin{array}{l}\text { No } \\
\text { No (\%) }\end{array}$} & \multirow{2}{*}{$\begin{array}{l}\text { Yes } \\
\text { No (\%) }\end{array}$} & \multirow[b]{2}{*}{ p Value } \\
\hline \multicolumn{2}{|c|}{ Statement } & & & & & & \\
\hline \multirow[t]{3}{*}{1} & Disagree* $^{*}$ & $10(8.6)$ & $19(20.0)$ & 0.01 & $20(20.2)$ & $9(8.3)$ & 0.005 \\
\hline & Neutral & $24(20.5)$ & $26(27.4)$ & & $28(28.3)$ & $21(19.3)$ & \\
\hline & Agree & $83(70.9)$ & $50(52.6)$ & & $51(51.5)$ & 79 (72.5) & \\
\hline \multirow[t]{3}{*}{2} & Disagree & 33 (28.2) & $47(50.0)$ & 0.0001 & $42(42.4)$ & 37 (33.9) & 0.05 \\
\hline & Neutral & $29(24.8)$ & $29(30.9)$ & & 31 (31.3) & $26(23.9)$ & \\
\hline & Agree & 55 (47.0) & 18 (19.2) & & 26 (26.3) & 46 (42.2) & \\
\hline \multirow[t]{3}{*}{3} & Disagree & 19 (16.2) & $8(8.6)$ & 0.24 & $14(14.1)$ & $12(11.1)$ & 0.26 \\
\hline & Neutral & $27(23.1)$ & $21(22.6)$ & & $27(27.3)$ & $21(19.4)$ & \\
\hline & Agree & $71(60.7)$ & 64 (68.8) & & $58(58.6)$ & $75(69.4)$ & \\
\hline \multirow[t]{3}{*}{4} & Disagree & 38 (33.3) & 31 (33.7) & 0.81 & 30 (31.3) & 37 (34.9) & 0.57 \\
\hline & Neutral & $29(25.4)$ & 20 (21.7) & & $26(27.1)$ & $22(20.8)$ & \\
\hline & Agree & $47(41.2)$ & $41(44.6)$ & & 40 (41.7) & $47(44.3)$ & \\
\hline \multirow[t]{3}{*}{5} & Disagree & $27(24.1)$ & $47(51.1)$ & 0.0001 & $42(43.8)$ & $32(30.5)$ & 0.05 \\
\hline & Neutral & $22(19.6)$ & 17 (18.5) & & $20(20.8)$ & $18(17.1)$ & \\
\hline & Agree & 63 (56.3) & $28(30.4)$ & & $34(35.4)$ & 55 (52.4) & \\
\hline \multirow[t]{3}{*}{6} & Disagree & $38(33.6)$ & 22 (23.9) & 0.28 & $35(36.5)$ & $24(22.9)$ & 0.07 \\
\hline & Neutral & $23(20.4)$ & 19 (20.7) & & $20(20.8)$ & $21(20.0)$ & \\
\hline & Agree & $52(46.0)$ & $51(55.4)$ & & 41 (42.7) & $60(57.1)$ & \\
\hline
\end{tabular}

*For the purposes of these analyses, the answers "disagree" and "strongly disagree" are combined, as are "agree" and "strongly agree." There were no consistent significant relations between the responses given and the age of the patient, their country of birth, language spoken, or previous attendance at a sexual health or GUM clinic. 
more likely to feel comfortable, it may be appropriate to ask these individuals to attend designated teaching clinics.

The most common reasons given by our patients for feeling discomfort with students were privacy and concerns of a lower standard of care. Both of these factors may be reversible to some degree through better explanation of the student's role.

Our study examines patients' attitudes towards students, rather than actual refusal to see students. It is possible our findings do not directly reflect the proportion of patients who would accept medical students in their consultation. The finding that non-English speaking patients, and those born overseas, are no more likely to feel discomfort with medical students provides some support that our findings will apply in other GUM clinics. The questionnaire was only available in English, introducing a potential bias, however, this was reduced because of the high response rate and availability of interpreters to assist patients.

Our findings suggest that without active allocation of those patients who feel comfortable with medical students to training clinics a large proportion of patients will experience discomfort and many students, especially males, will have an unsatisfactory clinical experience. By advising patients of the presence of students, and explaining their role, patient discomfort may be minimised and students' clinical experiences will be more rewarding.

\section{ACKNOWLEDGEMENTS}

The authors acknowledge the assistance of the Marlborough Clinic staff for their assistance in administering the questionnaires.

\section{CONTRIBUTORS}

NR designed the questionnaires, organised the conduction of the study and prepared the manuscript; DI conceived the study and edited the manuscript; CS performed the statistical analysis and cowrote the results section of the paper.

\section{Authors' affiliations}

N Ryder, D Ivens, C Sabin, Marlborough Clinic, Royal Free Hospital, Pond Street, London NW3 2QG, UK

\section{REFERENCES}

1 Simons R, Imboden E, Martel J. Patient attitudes toward medical student participation in a general medicine clinic. J Gen Intern Med 1995;10:251-4.

2 Ching S, Gates E, Robertson P. Factors influencing obstetric and gynecologic patients' decisions toward medical student involvement in the outpatient setting. Am J Obstet Gynecol 2000;182:1429-32.

3 Hartz B, Beal J. Patients' attitudes and comfort levels regarding medical students' involvement in obstetrics-gynecology outpatients clinics. Acad Med 2000;75:1010-14.

4 Cowan F, Adler M. Survey of undergraduate teaching in genitourinary medicine in Britain. Genitourin Med 1994;70:311-13.

5 Adler M. Survey of medical undergraduate teaching in genitourinary medicine in Britain. Genitourin Med 1986;62:405. 